\title{
Is the formation of ocular dominance patterns instructed by molecular labels?
}

\author{
Dmitry Tsigankov*1,2,3 and Alexei Koulakov ${ }^{3}$
}

\author{
Address: ${ }^{1}$ Department of Nonlinear Dynamics, Max-Planck-Institute for Dynamics and Self-Organization, D37073 Göttingen, Germany, \\ ${ }^{2}$ Bernstein Center for Computational Neuroscience, D37073 Göttingen, Germany and ${ }^{3}$ Cold Spring Harbor Laboratory, Cold Spring Harbor, NY \\ 11724, USA \\ Email: Dmitry Tsigankov* - dmitry@nld.ds.mpg.de \\ * Corresponding author
}

from Eighteenth Annual Computational Neuroscience Meeting: CNS*2009

Berlin, Germany. 18-23 July 2009

Published: 13 July 2009

BMC Neuroscience 2009, I0(Suppl I):P65 doi:I0.I I86/I47I-2202-I0-SI-P65

This abstract is available from: http://www.biomedcentral.com/I47I-2202/I0/SI/P65

(c) 2009 Tsigankov and Koulakov; licensee BioMed Central Ltd.

The formation of ocular dominance patterns in visual cortex is thought to be driven by electrical activity of the projecting LGN neurons. Indeed, theoretical modeling has shown that lateral cortical activity-dependent interactions are capable of producing such a periodic pattern of regions dominated by inputs from left or right eye [1]. In this view, the ocular dominance emerges from the interplay of excitatory and inhibitory connections. The major characteristic of these structures, the width of the ocular dominance regions, is then determined by the spatial profile of the lateral interactions. Experimental attempts to confirm this view by altering the strength of the inhibitory connections have shown [2] that observed changes of the ocular dominance width are inconsistent with the model's central predictions. When the strength of inhibitory connections is increased and thus the characteristic length scale of the lateral interaction profile is decreased, the width of the ocular dominance was found to increase, indicating the opposite behavior to one predicted by the model. Here we resolve this paradox by investigating how other factors, such as interactions between chemical labels, can participate in the formation of ocular dominance patterns.

We introduce an energy of arbitrary connectivity configuration between projecting and receiving neurons that incorporates the contributions from activity-dependent mechanisms and interactions between chemical labels.
We apply this unifying description [3] to find the ground state configuration for two identical sets of projecting neurons with the same expression of chemical cues but uncorrelated electrical activity. The single gradient of the chemical labels is taken for both target and projecting neurons following the experimentally observed expression patterns. We then analyze the analytical dependence of optimal width of the ocular dominance pattern on the strength of interactions and their spatial scales.

We show that the interaction of projecting neurons with a single gradient of chemical labels combined with correlation-based activity-dependent interaction between neurons results in the formation of ocular dominance structure. We find that the period of ocular dominance depends on relative strength of two interactions and the ratio of their characteristic length scales. We obtain two different regimes when the emerging width of ocular dominance is bigger or smaller than the characteristic length of lateral interactions. The effect of changing the length scale for lateral interactions on the width of ocular dominance is opposite in two regimes: it increases in one of them and decreases in another following the same manipulation, depending on the strength of chemical gradients.

Our results show that in the presence of gradients of chemical labels the width of the ocular dominance pat- 
terns is not solely determined by the length scale of lateral cortical interactions. In the case of large gradients, we find a novel regime when the lateral connections span across several ocular dominance periods. In this regime, enhancement of inhibitory lateral connections results in increase of the width of the ocular dominance pattern in agreement with experimental observations [2]. The presented analytical model thus provides a useful framework for study of the interplay between genetically encoded expression of chemical labels and experience dependent plasticity in the formation of ocular dominance patterns.

\section{Acknowledgements}

Matthias Kachube (Princeton University) for useful discussions and Fred Wolf (Max-Planck Institute for Dynamics and Self-Organization) for introducing the authors to existing paradox in theory of ocular dominance formation.

\section{References}

I. Miller KD, Keller JB, Stryker MP: Ocular dominance column development: analysis and simulation. Science 1989, 245:605-6I5.

2. Hensch TK, Stryker MP: Columnar architecture sculpted by GABA circuits in developing cat visual cortex. Science 2004, 303:1678-168I.

3. Tsigankov DN, Koulakov AA: A unifying model for activitydependent and activity-independent mechanisms predicts complete structure of topographic maps in ephrin-A deficient mice. J Comput Neurosci 2006, 2 1:101-II4.

Publish with Bio Med Central and every scientist can read your work free of charge

"BioMed Central will be the most significant development for disseminating the results of biomedical research in our lifetime. "

Sir Paul Nurse, Cancer Research UK

Your research papers will be:

- available free of charge to the entire biomedical community

- peer reviewed and published immediately upon acceptance

- cited in PubMed and archived on PubMed Central

- yours - you keep the copyright

Submit your manuscript here:

http://www.biomedcentral.com/info/publishing_adv.asp 